\title{
MALIGNANT FIBROUS HISTIOCYTOMA OF THE HEART PRODUCING INTERLEUKIN-6
}

Hajime Matsue, MD, ${ }^{a}$ Tetsuo Sakakibara, MD, ${ }^{\text {a }}$ Ryousuke Matsuwaka, MD, ${ }^{\text {a }}$ Masataka Mitsuno, MD, ${ }^{\text {a }}$ Masahiko Tsujimoto, MD, ${ }^{\mathrm{b}}$ and Norihiro Nishimoto, MD, ${ }^{\mathrm{c}}$ Osaka, Japan

Malignant fibrous histiocytoma (MFH) is one of the most common soft tissue sarcomas. However, MFH is uncommon as a primary cardiac tumor. Here we report a case of primary $\mathrm{MFH}$ of the heart producing the inflammatory cytokine interleukin-6 (IL-6).

Clinical summary. A 54-year-old man was admitted to our hospital with high fever and arthralgia of the lower extremities of 1 month's duration. Examination showed severe edema of the face and extremities. He became orthopneic and his cardiac status deteriorated to New York Heart Association functional class IV soon after admission. Laboratory tests gave the following data showing severe inflammation: the leukocyte count was $14.9 \times 10^{3} / \mu \mathrm{l}$, the C-reactive protein level was $23.37 \mathrm{mg} / \mathrm{dl}$, and the serum IL-6 level, measured by chemiluminescent enzyme immunoassay (Human IL-6 CLEIA, Fujirebio Corp., Tokyo, Japan), was an extremely high $61.4 \mathrm{pg} / \mathrm{ml}$ (normal range: 0 to $3.0 \mathrm{pg} / \mathrm{ml}$ ). The electrocardiogram showed atrial fibrillation. Transthoracic and transesophageal echocardiography revealed a huge tumor in the left atrium, which was attached to the intraatrial septum and extended to the anterior leaflet of the mitral valve (Fig. 1). Other examinations revealed no abnormalities. Because of these data, a cardiac myxoma was strongly suspected.

The tumor was excised via the transseptal superior approach with the aid of cardiopulmonary bypass. The mass was removed piecemeal with the involved portion of the intraatrial septum, and the resulting defect was repaired with a polytetrafluoroethylene cardiovascular patch. ${ }^{*}$ The tumor measured $8 \times 4 \times 3 \mathrm{~cm}$ and its surface was irregular. On sectioning, it was a solid lesion with areas of necrosis. Malignancy was diagnosed by the intraoperative pathologic examination. The carly

From the Division of Cardiovascular Surgery, Cardiovascular Center, ${ }^{a}$ Department of Pathology, ${ }^{b}$ Osaka Police Hospital, and the First Department of Medical Science, School of Health and Sport Sciences, Osaka University, ${ }^{\circ}$ Osaka, Japan.

Received for publication March 19, 1998; accepted for publication March 26, 1998.

Address for reprints: Tetsuo Sakakibara, MD, Cardiovascular Surgery, Osaka Police Hospital, 10-31, Kitayamacho, Tennojiku, Osaka 543-0035, Japan.

"Gore-Tex patch, registered trademark of W. L. Gore \& Associates, Inc., Flagstaff, Ariz.

J Thorac Cardiovasc Surg 1998;116:522-4

Copyright $(\subset) 1998$ by Mosby, Inc.

$0022-5223 / 98 \$ 5.00+0 \quad \mathbf{1 2 / 5 4 / 9 0 6 6 2}$ postoperative period was uneventful. The fever resolved and the arthralgia and edema disappeared. The C-reactive protein level was $10.57 \mathrm{mg} / \mathrm{dl}$ and serum IL-6 was $29.9 \mathrm{pg} / \mathrm{ml} 3$ weeks after the operation. On culture of tumor cells, IL-6 release into the supernatant was $2600 \mathrm{ng} / \mathrm{ml}$ in 8 hours. Microscopic examination revealed poorly differentiated tumor cells with hyperchromatic and pleomorphic nuclei, spindle-shaped cells arranged in a stria pattern, and multinucleated giant cells (Fig. 2, A). Immunostaining with an antibody to $\alpha_{1}$-antichymotrypsin showed dark reaction products in some of the tumor cells (Fig. 2, B). From these histologic findings, the tumor was finally diagnosed as MFH of the heart. Adjunctive radiation therapy to the left atrium was then performed.

On postoperative day 40, high fever and edema again developed. Transthoracic echocardiography showed local recurrence of the tumor in the left atrium. Laboratory tests showed a leukocyte count of $10.9 \times 10^{3} / \mu \mathrm{l}$, a C-reactive protein level of $25.82 \mathrm{mg} / \mathrm{dl}$, and a serum IL-6 level of $133.7 \mathrm{pg} / \mathrm{ml}$. He died of left heart failure on postoperative day 70 . Autopsy revealed a recurrent tumor occupying a large part of the left atrium and obstructing the mitral valve, with metastases to the bilateral adrenal glands and the right foot.

Comment. It was recently reported that cardiac myxoma cells produced IL-6, which could causc a systemic inflammatory response, including fever, arthralgia, and increased levels of acute-phase proteins. ${ }^{1,2}$ Soeparwata and colleagues ${ }^{3}$ reported a significant correlation between the serum IL-6 level and tumor size and stated that constitutional symptoms appeared at an IL-6 level of 9 $\mathrm{pg} / \mathrm{ml}$ or more. Because our patient had a tumor in the left atrium and inflammatory manifestations, we thought of the possibility of increased serum levels of inflammatory cytokines. As we expected, the IL-6 level in serum and tumor cell culture supernatant was extremely high, and the serum IL-6 level decreased after tumor resection and increased again at the time of recurrence. These findings indicated that the patient's tumor produced IL-6. Thus measurement of inflammatory cytokines such as IL-6 might be helpful to clarify the pathophysiology when a cardiac tumor is found in association with constitutional signs and symptoms.

MFH is the most common soft tissue sarcoma arising from various organs, but primary $\mathrm{MFH}$ of the heart is extremely unusual. ${ }^{4}$ According to a review of the literature on primary MFH of the heart, 22 of 26 tumors were in the left atrium, and the prognosis of 14 patients having surgical resection was very poor. ${ }^{5}$ It appears that cardiac MFH should be resected as radically as possible, but no standard adjuvant chemotherapy or irradiation regimen has been developed because this tumor is extremely uncommon. ${ }^{5}$ So far as we know, there has been no 


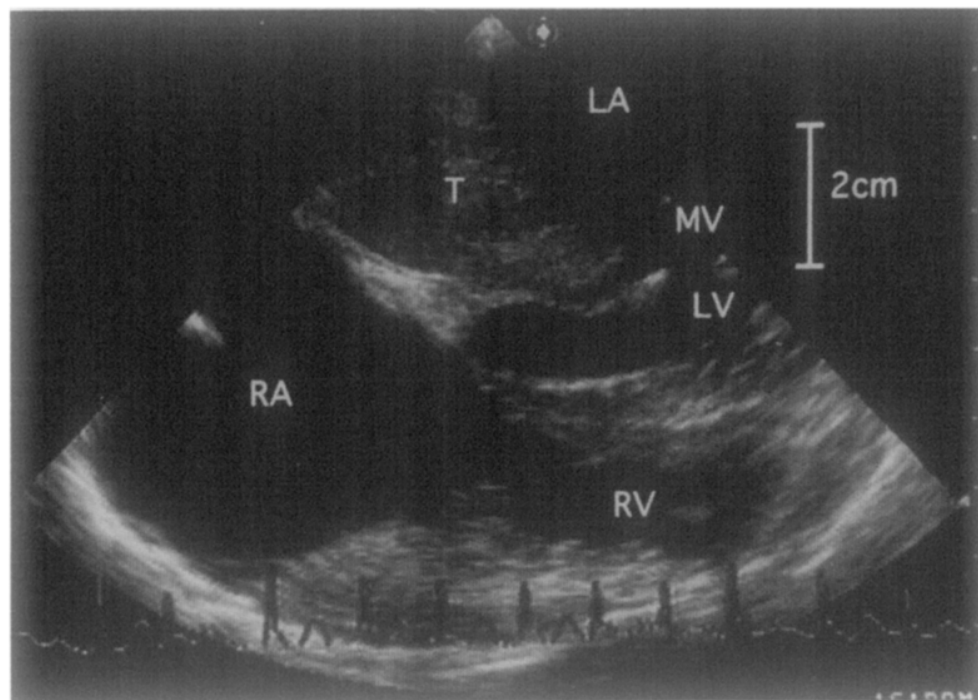

Fig. 1. Transesophageal echocardiogram showed a huge tumor $(T)$ in the left atrium $(L A)$, which was attached to the intraatrial septum and extended to the anterior leaflet of the mitral valve $(M V) . L V$, Left ventricle; $R A$, right atrium, $R V$, right ventricle.
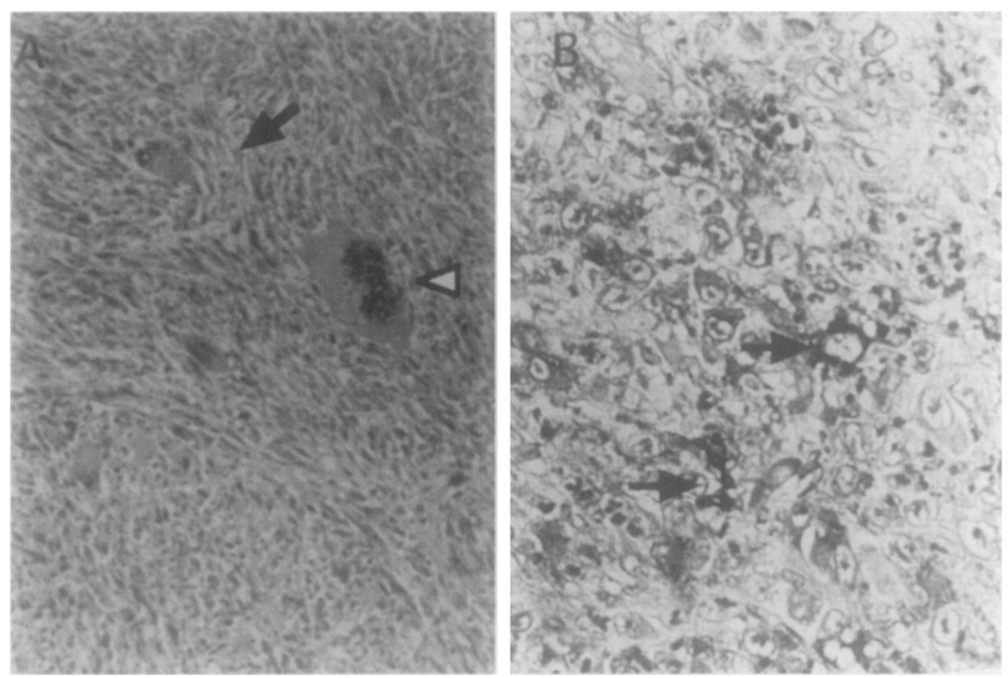

Fig. 2. A, Hematoxylin-eosin-stained section showing poorly differentiated tumor cells with a striated pattern (arrow) and a multinucleated giant cell (arrowhead). B, Immunostained section showing $\alpha_{1}$ antichymotrypsin positive cells (arrow).

previous report of cardiac MFH producing IL-6, as in our case. The fact that local recurrence developed soon after the operation in our case suggests that a more extensive operation may have been desirable, such as total resection and replacement of the intraatrial septum. Heart transplantation is a yet more radical treatment than conventional tumor resection, although the use of donor hearts for patients with a possibly poor prognosis is the subject of controversy. Partial or total cardiac replacement with the use of sophisticated artificial technology may be an option in the futurc.

\section{REFERENCES}

1. Hirano T, Taga T, Yasukawa K, Nakajima K, Nakano N Takatsuki $F$, et al. Human B-cell differentiation factor defined by an anti-peptide antibody and its possible role in autoantibody production. Proc Natl Acad Sci U S A 1987; $84: 398-402$ 
2. Saji T, Yanagawa E, Matsuura $H$, Yamamoto $S$, Ishikita $T$, Matsuo $\mathrm{N}$, et al. Increased serum interleukin-6 in cardiac myxoma. Am Heart J 1991;122:570-80.

3. Soeparwata R, Poeml P, Schmid C, Neuhof H, Scheld HH. Interleukin-6 plasma levels and tumor size in cardiac myxoma. J Thorac Cardiovasc Surg 1996;112:1675-7.
4. Laya MB, Mailliard JA, Bewtra C, Levin HS. Malignant fibrous histiocytoma of the heart: a case report and review of the literature. Cancer 1987;59:1026-31.

5. Korbmacher B, Doering C, Schulte HD, Hort W. Malignant fibrous histiocytoma of the heart-case report of a rare left-atrial tumor. Thorac Cardiovasc Surg 1992;40:303-7.

\title{
LEFT THORACODORSAL ARTERY AS AN INFLOW GRAFT FOR MINIMALLY INVASIVE DIRECT CORONARY ARTERY BYPASS GRAFTING
}

\author{
Go Watanabe, MD, Takuro Misaki, MD, Keijyu Kotoh, MD, and Katsushi Ueyama, MD, Toyama, Japan
}

The thoracodorsal artery (TDA) is one of the branches of the subscapular artery that is the largest branch of the axillary artery. It arises from the third part of the axillary artery and runs in a downward and medial direction along the anterior border of the subscapularis and under the cover of the latissimus dorsi muscle. In the field of dynamic cardiomyoplasty and plastic surgery, the TDA has been used to supply muscle or musculocutaneous flap. ${ }^{1,2}$ The TDA has an attractive caliber and length as an arterial graft. We report the first case in which an in situ TDA was used as an inflow graft for myocardial revascularization.

The patient was a 68-year-old woman with a history of increasing postinfarction angina and cerebral infarction. Cardiac catheterization revealed $90 \%$ stenoses of the proximal left anterior descending artery (LAD) and of an obtuse marginal branch of circumflex coronary artery (OM). Minimally invasive coronary artery bypass grafting (MIDCAB) through a small thoracotomy via the left internal thoracic artery (LITA) and the right gastroepiploic artery was planned to revascularize the LAD and OM. However, the preoperative angiogram had shown total occlusion of the celiac artery. We decided to avoid grafting the right gastroepiploic artery. We concluded that the left TDA could be used as an inflow graft to bypass the OM. The patient was placed in the right lateral position; the LITA was harvested thoracoscopically as a pedicle with the use of video imaging guidance. An incision of approximately $3 \mathrm{~cm}$ was made over the fourth intercostal space along the

From the Department of Surgery, Toyama Medical and Pharmaceutical University, Toyama, Japan.

Received for publication March 2, 1998; accepted for publication April 13, 1998.

Address for reprints: Go Watanabe, MD, Department of Surgery, Toyama Medical and Pharmaceutical University, Sugitani, Toyama 2630, 930-01, Japan.

J Thorac Cardiovase Surg 1998;116:524-5

Copyright (C) 1998 by Mosby, Inc. $0022-5223 / 98 \$ 5.00+0 \quad \mathbf{1 2 / 5 4 / 9 0 8 8 1}$

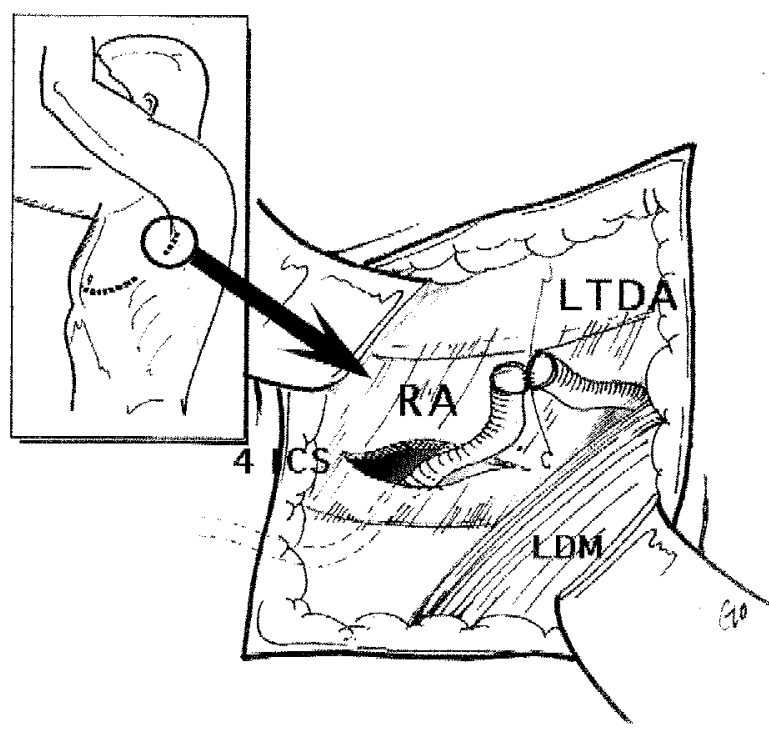

Fig. 1. The minithoracotomy consisted of limited lateral thoracotomy incision in the fifth intercostal space (ICS) and small axillary incision for the left thoracodorsal artery (LTDA) harvesting. LDM, Latissimus dorsi muscle.

anterior margin of the left latissimus dorsi muscle (Fig. 1). The TDA courses between the latissimus dorsi muscle and the serratus anterior muscle and was easily visualized when the latissimus dorsi muscle was retracted laterally. We carefully isolated $8 \mathrm{~cm}$ of the TDA. The diameters of the distal portion of the TDA were $2.5 \mathrm{~mm}$. The size and quality of this artery were similar to those of the LITA in this case. A limited lateral thoracotomy incision was performed in the fifth intercostal spacc; thereafter, the right radial artery (RA) was also harvested. The left TDA was divided distally after heparinization and anastomosed to the free RA with an 8-0 suture. The TDA-RA compositc graft was introduced through the fourth intercostal space via the major fissure of the left lung. Stay sutures 